\title{
Resonant Electromagnetic Processes at Unstable Operation of Sliding Current Collector Units of Turbogenerator
}

\author{
Igor Plokhov \\ Department of Electric Power \\ Engineering, Electric Drive and \\ Automation Systems \\ Pskov State University \\ Pskov, Russia \\ igor_plohov@list.ru \\ Oksana Kozyreva \\ Department of Electric Power \\ Engineering, Electric Drive and \\ Automation Systems \\ Pskov State University \\ Pskov, Russia \\ ks_33n@mail.ru
}

\author{
Igor Savraev \\ Department of Electric Power \\ Engineering, Electric Drive and \\ Automation Systems \\ Pskov State University \\ Pskov, Russia \\ igor_savraev@mail.ru
}

\author{
Alexander Dementiev \\ Institute of Engineering \\ Pskov State University \\ Pskov, Russia \\ techno@pskgu.ru
}

\author{
Alexander Ilyin \\ Department of Electric Power \\ Engineering, Electric Drive and \\ Automation Systems \\ Pskov State University \\ Pskov, Russia \\ al.ilyin@yandex.ru
}

\begin{abstract}
The article is devoted to study of the resonance electromagnetic oscillations arising during unstable operation of the sliding current collection unit of turbogenerators. Mathematical modeling of these processes is carried out. It has been established that it is these processes that are the main cause of increased sparking and "ring fire" or "breakdown of commutation" on contact rings.
\end{abstract}

Keywords - sliding current collector units, resonance, mathematical model, computer simulation.

\section{INTRODUCTION}

The operation of sliding electrical contacts (SC) is accompanied by mechanical vibrations causing modulation of current flowing through the contact. If the disturbing influences exceed pressing force on the brush, the current transmission becomes unstable, currentless pauses appear [1]. During the operation of parallel sliding electrical contacts, specified disturbances can occur simultaneously at some part of brushes.

In DC electric machines, the main cause of brush sparking is the commutation process. For current collector assemblies with slip-ring contacts, the causes of sparking have so far not been adequately explained. Attempts to explain the sparking on the contact rings [2] boil down mainly to the fact that due to the high current density in the transition layer of SC causes melting and evaporation of the surface layers of the contact parts, leading to the release of red-hot particles in the direction of rotation of the contact rings (CR). However, the release of particles occurs only at very high levels of sparking. It is impossible to explain in the indicated way the most common point sparking and increased sparking under the entire running edge of the SC without the release of sparks. In addition, thermal calculations show [3] that the temperatures of contact clusters in the transition layer of SC very rarely reach the melting and evaporation temperatures of SC materials (steel and graphite: $1500-3200{ }^{\circ} \mathrm{C}, \quad 3900$ $4200^{\circ} \mathrm{C}$ ). A spark discharge cannot occur when the voltage drop on the contact is $2.5-3 \mathrm{~V}$. To ensure the breakdown of the air gap and dielectric surface membranes, kilovolts of voltage are required, which occur in the modes of parametric resonances. There is a very indicative practical case of fighting the circular fire, which leads to the conclusion about insufficiency of theoretical substantiation of causes of increased sparking and circular fire [2, 4, 5]. At the request of the management of the power plant, the 
authors of this brochure [2] did not indicate the reasons for the occurrence of an all-round fire in the brush-contact apparatus of a new turbogenerator with a capacity of $500 \mathrm{MW}$, despite promptly accepting (flow-through, "repolarization", sealing of the brush-contact apparatus (BCA), purging, cleaning of a ring, replacement of brushes and etc.). Sparking on the negative ring appeared in January 2010 and was observed constantly, despite the measures taken. After 1.5 months, an emergency shutdown occurred due to strong sparking on the negative (inner) ring. The slip rings were sanded, the polarity was changed (the outer ring - negative, the inner one - positive), and the EG-2AF1 type brushes were replaced with 6110M type brushes. Since oil from the bearing had previously penetrated into the BCA measures were taken to prevent oiling of the rings. Then the second emergency shutdown of the generator occurred 10 days after the first due to strong sparking also on the negative (in this case, already on the outer) ring. Again the rings were polished and the polarity of the rings reversed (the outer ring - plus and the inner ring - minus.).To prevent possible oil ingress into the BCA, a new sealing of BCA was installed on the bearing side, an oil trap was upgraded, and cloth filters were installed at the air inlet to the BCA. However, the measures taken did not give any result and the third emergency shutdown occurred due to the all-round fire again on the negative slip ring 9 days after the second shutdown. Its vibration before the shutdown was 298-320 microns. The wear of the brushes on the ring was increased: they fell into disrepair 2 hours after installation. After the turbogenerator was stopped, the inner ring was sanded again. As a result, due to repeated grinding, its diameter has decreased unacceptably. The serviceability of thyristors was repeatedly checked. There were no comments relating to any faults. A transition was made from the working excitation to the reserve (electric machine exciter), but the sparking was not eliminated. After 7 months after the repairs carried out, strong sparking reappeared due to which the generator had to be stopped.

This practical example clearly shows that there are hidden reasons for increased sparking and all-round fire that are not described in instructions and other literature. The authors of this paper found that these reasons are highamplitude parametric resonances in the electromagnetic circuits of the BCA. When the sparking brushes were shunted with a damping capacitance, the sparking almost completely disappeared, which indicates the importance of electromagnetic resonance causes of sparking [6, 7].

Practice shows that sparking on contact rings usually occurs with unbalanced distribution of current over parallel brushes [8], low quality of contact surface of the rings and increased vibration of the electric machine. These factors are external visible causes of sparking, but it is more important to identify internal energy release mechanisms in the contact layer. This will allow the development of new methods for reducing sparking in the BCA of the turbogenerator.
As the measurements show, the sliding contact has an electric capacity which varies within thousands and hundreds of $\mu \mathrm{F}$ depending on the type of brush and its mode of operation. The "direct" contact intervals are characterized by the largest value of contact capacity, which is shunned by the small transition resistance of one hundred and one thousand fractions of Ohm for various SC. In case of contact failure, the flow of power current in the transition layer is practically stopped, the transition resistance reaches units and tens of $\mathrm{kOhm}$, and the contact capacity is reduced due to the increase in the distance between the contacting micro-reliefs. In addition, the current conductors, together with the accompanying current conducting elements, have a resistance of microOhm and an inductance ranging from one to hundreds of micro-Henry.

\section{SIMULATION OF THE DYNAMICS OF CURRENT DISTRIBUTION}

Based on the above considerations, we will construct an design model of the group SC. The brushes are divided into two groups: 1) contacting continuously; 2) contacting with the probability of current transmission failure.

Let's consider the replacement scheme of the sliding current collector unit (SCCU) of the turbo generator and its mathematical description.

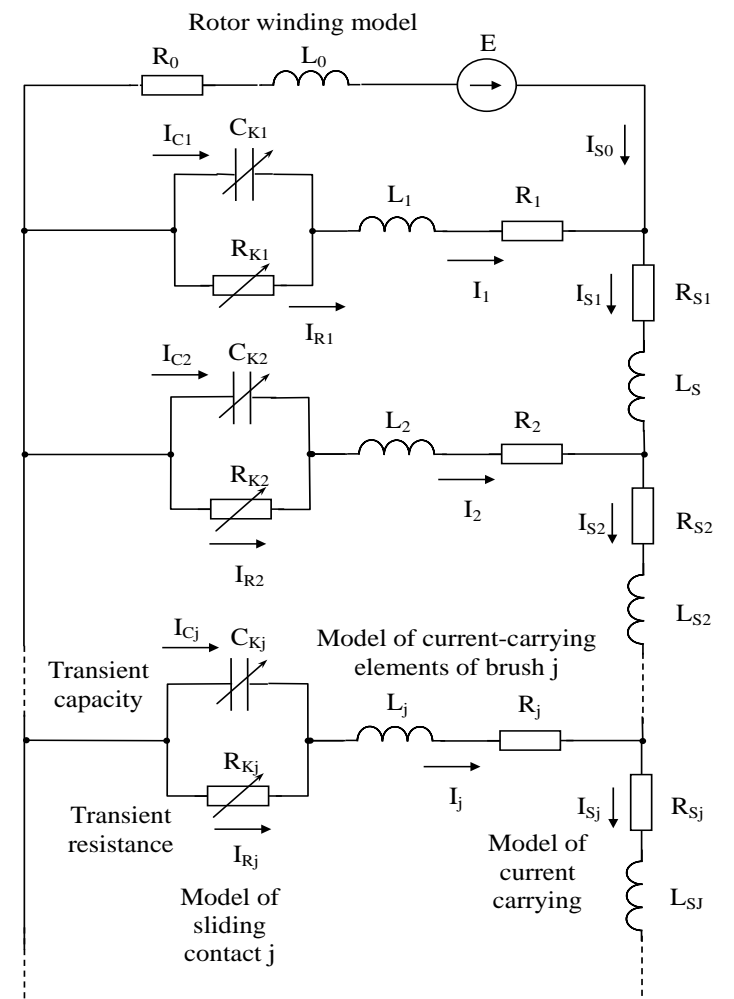

Fig. 1. General replacement scheme of sliding current collection unit.

The dynamics of current distribution will be described by the system of differential equations 
Environment. Technology. Resources. Rezekne, Latvia Proceedings of the $13^{\text {th }}$ International Scientific and Practical Conference. Volume 3, 281-285

$$
\left\{\begin{array}{c}
I_{0} R_{0}+L \frac{d I_{0}}{d t}+I_{1} R_{1}+L \frac{d I_{1}}{d t}+I_{R 1} R_{K 1}=E \\
I_{j+1} R_{j-1}+L_{j-1} \frac{d I_{j-1}}{d t}+I_{R j-1} R_{K j-1}- \\
-I_{j} R_{j}-L_{j} \frac{d I_{j}}{d t}-I_{R j} R_{K j}-I_{S j-1} R_{S j-1}- \\
-L_{S j-1} \frac{d I_{S j-1}}{d t}=0 \\
I_{j} R_{j}+L_{j} \frac{d I_{j}}{d t}+I_{R j} R_{K j}-I_{j+1} R_{j+1}- \\
-L_{j+1} \frac{d I_{j+1}}{d t}-I_{R j+1} R_{K j+1}-I_{S j} R_{S j}- \\
-L_{S j} \frac{d I_{S j}}{d t}=0 \\
I_{S j-1}-I_{j}-I_{S j}=0, \sum_{j} I_{j}-I_{0}=0 \\
I_{R j} R_{K j}-\frac{1}{C_{K j}} \int U_{c j} d t=0
\end{array}\right.
$$

Parameters $R_{K j}$ and $C_{K j}$ are transient resistance and SC capacity depend on contact pressure, which is modulated by kinematic perturbation effects:

For simplicity, let's consider the characteristics of the system with two SC in a parallel branch, each of which can be represented as a synchronously operating group of contacts. Moreover, in the process of simulation we will conditionally set the transient resistance and capacity of the stable group of brushes constant, and for the unstable group we introduce modulation of these parameters: sinusoidal, polyharmonic, relay or pulse.

The scheme of replacement of the CCU comprising two brushes in a parallel branch is shown in Fig. 2.

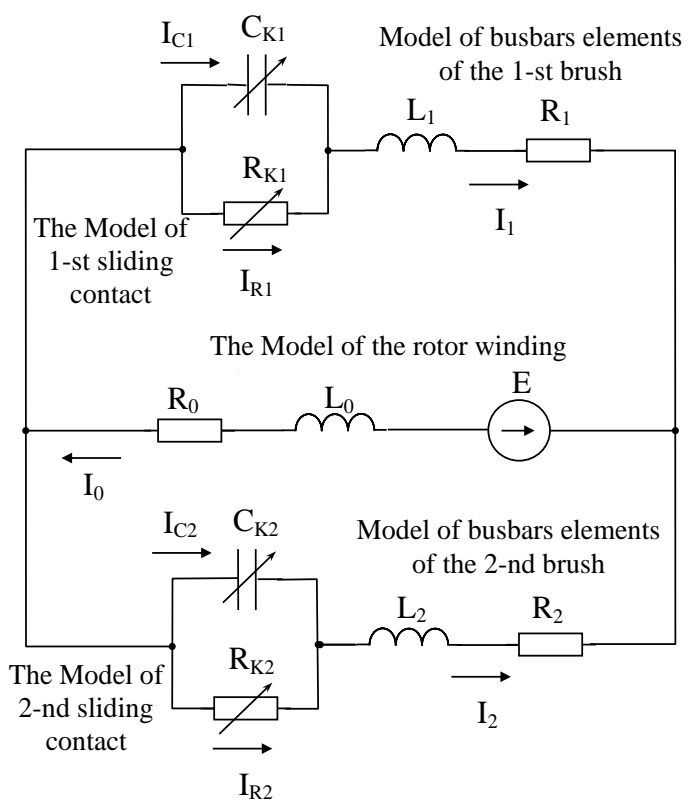

Fig. 2. The scheme of replacement of sliding current collection unit comprising two sliding contacts or two groups of SC.

Let's describe the dynamics of current distribution by the system of integro-differential equations

$$
\left\{\begin{array}{c}
I_{1} R_{1}+L_{1} \frac{d I_{1}}{d t}+I_{R 1} R_{K 1}+I_{0} R_{0}+L_{0} \frac{d I_{0}}{d t}=E \\
I_{2} R_{2}+L_{2} \frac{d I_{2}}{d t}+I_{R 2} R_{K 2}+I_{0} R_{0}+L_{0} \frac{d I_{0}}{d t}=E \\
I_{R 1} R_{K 1}-\frac{1}{C_{K 1}} \int_{0}^{T} I_{C 1} d t=0 \\
I_{R 2} R_{K 2}-\frac{1}{C_{K 2}} \int_{0}^{T} I_{C 2} d t=0 \\
I_{1}+I_{2}-I_{0}=0 \\
I_{1}-I_{C 1}-I_{R 1}=0 \\
I_{2}-I_{C 2}-I_{R 2}=0
\end{array} .\right.
$$

We will bring this system to the operator form

$$
\left\{\begin{array}{c}
I_{1}(p)=\frac{1}{p} \frac{1}{L_{1}}\left[E-I_{1}(p) R_{1}-\right. \\
\left.-I_{R 1}(p) R_{K 1}-I_{0}(p) R_{0}\right]-I_{0}(p) \frac{L_{0}}{L_{1}} \\
I_{2}(p)=\frac{1}{p} \frac{1}{L_{2}}\left[E-I_{2}(p) R_{2}-\right. \\
\left.-I_{R 2}(p) R_{K 2}-I_{0}(p) R_{0}\right]-I_{0}(p) \frac{L_{0}}{L_{2}} \\
I_{R 1}(p)=\frac{1}{p} I_{C 1}(p) \frac{1}{R_{K 1} C_{K 1}} \\
I_{R 2}(p)=\frac{1}{p} I_{C 2}(p) \frac{1}{R_{K 2} C_{K 2}} \\
I_{0}(p)=I_{1}(p)+I_{2}(p) \\
I_{C 1}(p)=I_{1}(p)-I_{R 1}(p) \\
I_{C 2}(p)=I_{2}(p)-I_{R 2}(p)
\end{array}\right.
$$

Using equations (3) we will construct a dynamic simulation model in the environment SIMULINK MATLAB (Fig. 3).

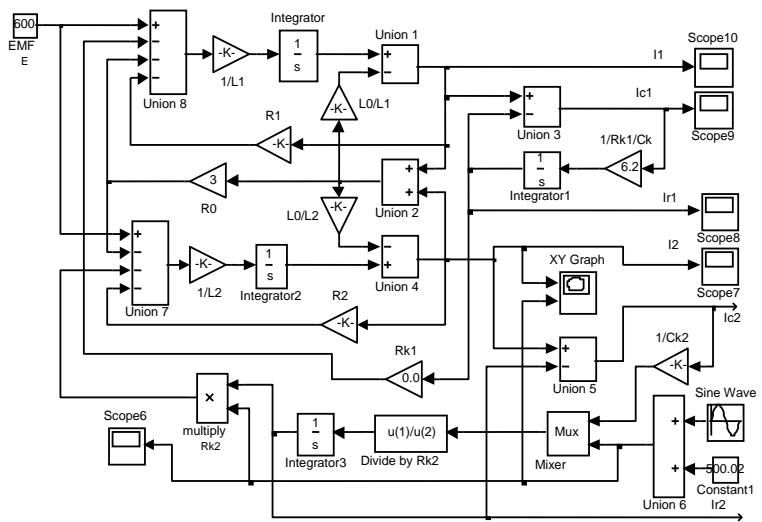

Fig. 3. Simulink-model of a current collection node with two SC or two groups of SC.

The model allows us to study dynamic processes occurring in parametric perturbations of various types. In this figure, in particular, a sine wave generator with a constant offset is used, the signal of which modulates the transient resistance of the brush. Under certain conditions, the system loses stability. As shown by the computational experiments the loss of stability and the sharp increase in the amplitudes of oscillating processes of current transmission are bound to the increase of instability of brush contact.

As an example, Fig. 4 shows the phase current trajectory $I_{2}(t)$ on the XY Graph plotter (Fig. 3) with a 
sinusoidally pulsating law of transient resistance variation of the second brush $R_{K 2}(t)$ within $0.02-1000 \mathrm{Ohm}$.

The oscillations of the output value ( $\mathrm{Y}$ axis) in a very short time acquire an amplitude exceeding $1000 \mathrm{~A}$ at a frequency of at least $1 \mathrm{MHz}$.

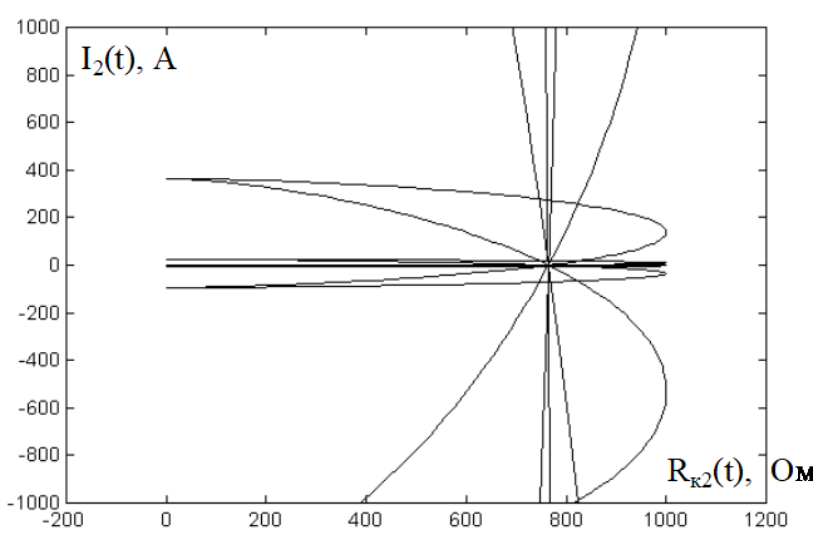

Fig. 4. Phase current trajectory $\mathrm{I}_{2}(\mathrm{t})$ calculated using the Simulinkmodel. It illustrates the characteristic picture of the development of divergent self-oscillating current distribution process in CCU.

Frequency dependency analysis shows that the system has resonance peaks the location and configuration of which depends on the $R_{K 2}$ and $C_{K 2}$ parameters. Since in the course of operation there is practically a relay periodic change of the specified parameters, which causes a change of all basic characteristics, the CCU can be classified as a class of dynamic systems with a variable structure (VSS) [8].

In our case, all the subsystems of the VSS being analyzed are stable, while the aggregate system is unstable in certain modes. This is due to the fact that the system has nonlinear characteristics of structural units and it is open. In open stochastic systems, synergistic phenomena associated with the formation of self-developing structures or processes arise under certain conditions [9] - [10]. The increase in quantitative changes can occur in an avalanchelike manner and with weak limiting factors lead to the destruction of the structure of the object.

Various computer simulation systems were used in the simulation process. The mode of divergent self-oscillating current distribution (DSCD) was revealed for all models.

\section{DSCD MODE AS A CAUSE OF CIRCULAR FIRE ON CONTACT RINGS}

A series of computational experiments using the Electronics Workbench simulation system from Interactive Image Technologies (Canada) was conducted to confirm the results and study the properties of the model.

It can be seen from the plots obtained during the simulation that the currents of brush groups in the mode of unstable contact take high instantaneous values exceeding nominal values by tens and hundreds of times. In addition, as shown by calculations higher harmonics of vibration acceleration have a major influence on the magnitude of current emissions. In this connection, the effect of frequency and duty cycle of regular SC disorders on the dynamic current distribution process was investigated (Fig. 5 and Fig. 6).

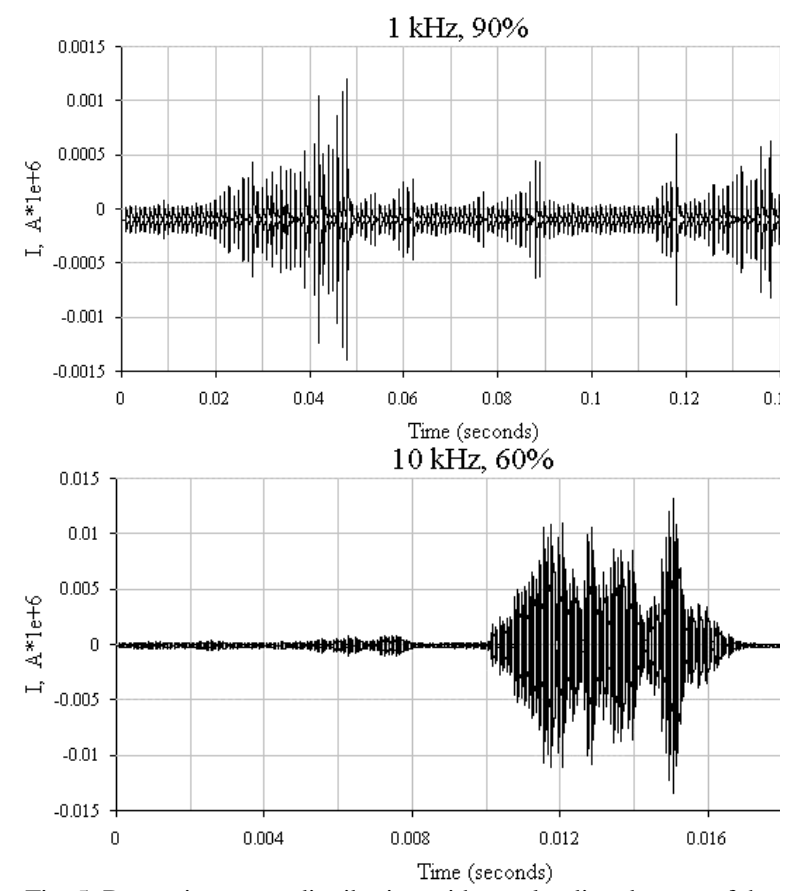

Fig. 5. Dynamic current distribution with regular disturbances of the sliding contact.

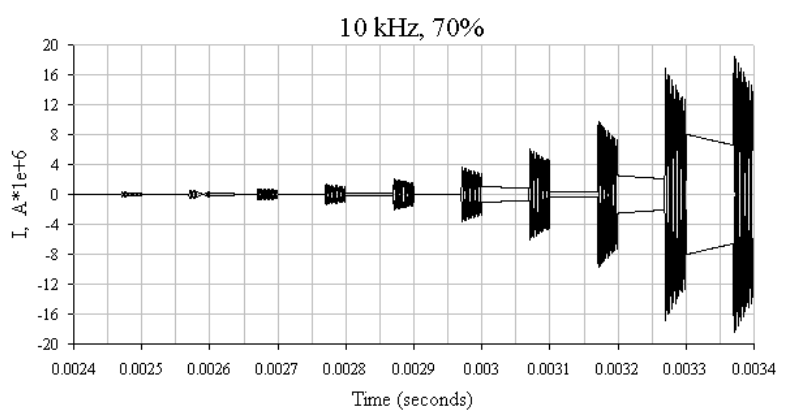

Fig. 6. Divergent process of dynamic current distribution.

Each of these graphs shows two curves, one shows the change in the current of the stable group of brushes, and the other demonstrates unstable current transmission with regular contact violations.

Based on the results of their analysis it can be said that there are combinations of duty cycle and frequency of contact violations in which current amplitudes reach very large values. Such processes should be accompanied by strong sparking of sliding contacts. In addition, a number of results were obtained in which the oscillatory process of dynamic current distribution became divergent, i.e. the system lost the stability.

To clarify the nature and dynamics of current distribution over several brush sets in conditions of unstable contact, the model was complicated. Five brush sets exposed to polyharmonic vibration accelerations, shifted in phase relative to each other in accordance with the placement of the sets along the perimeter of the contact 
ring, were introduced into consideration. The results obtained in this case confirmed the possibility of developing DSCD processes at certain harmonic perturbation compositions.

\section{CONCLUSIONS}

From the foregoing, it follows that diverging resonant electromagnetic processes of this type are one of the main electromagnetic causes of the occurrence of circular fire or "breakdown of commutation" at the contact rings of turbogenerators. Moreover, the probability of developing a divergent self-oscillating current distribution (DSCD) is the higher, the greater the instability of the contact of the BCA.

The result of the theoretical and experimental studies was the development of a method and a device for reducing sparking on the contact rings of the turbo-generator and excluding the emergency mode of the DSCD by introducing damping capacities into the electromagnetic circuits of the current collection unit, which reduce the amplitude of electromagnetic oscillations $[13,14]$.

It is possible to recommend the introduction of the above technique for analyzing the regions of electromagnetic resonances and a device for suppressing the sparking of the BCA for large power turbine generators.

\section{REFERENCES}

[1]. Mechanics of sliding contact / V.I.Nellin, N.Y.Bogatyrev, L.V.Lozhkin et al. - M.: Transport. 1966. 255 p. (in Russian).

[2]. Samorodov Y. N. Paradoxical properties of sliding contact in BCA. - M.: NTF “Energoprogress", 2013.56 p. (in Russian).

[13]. Device for reducing spark formation in the node of a sliding current collector / Plokhov I. V., Ilyin A.V., Isakov A. N., Kozyreva O. I. Patent for utility model No. 132630, publ.: 2013.09.20. (in Russian).

[14]. Device for reducing sparking in the sliding current collector assembly / Kotkov N. A., Plokhov I. V., Kozyreva O. I., Ilyin A.V., Savraev I. E. Patent for invention No. 2685695, publ.: 23.04.2019. (in Russian).
[3]. Ilyin, L., Plokhov I., Kozyreva, O., and etc. Synergetic model of electro-friction interaction. Environment. Technology. Resources. Rezekne, Latvia. Proceedings of the 12th International Scientific and Practical Conference, June 20-22, 2019. Volume III. P. 208213, http://dx.doi.org/10.17770/etr2019vol3.4072

[4]. Typical instructions for the operation and repair of the slip ring assembly and brush apparatus of turbine generators with a capacity of 63 MW and above. RD 153-34.0-45.510-98. M.: SPO ORGRES, 2000. (in Russian).

[5]. Braude L. I., Borozinets B. V., Maslov V. V. Operational control of serviceability of brush-contact devices of turbogenerators. - Electric power stations, 1998, No. 1. (in Russian).

[6]. Oksana Kozyreva, Igor Plokhov, Nikita Kotkov, and etc. Experimental investigations of effect of LC-circuits on sparking and thermal state of sliding electric contact unit. Environment. Technology. Resources, Rezekne, Latvia, Proceedings of the 11th International Scientific and Practical Conference. Volume III, 2017. P.150-153, http://dx.doi.org/10.17770/etr2017vol3.2575

[7]. Oksana Kozyreva, Igor Plokhov, Igor Savraev, and etc. Reducing sparking in the transient layer of the sliding electrical contact unit. 19th International Scientific Conference on Electric Power Engineering, Brno, Czech Republic, 16-18 May 2018. P.223-227, https://dx.doi.org/10.1109/EPE.2018.8395969

[8]. Popov I. N., Zrazhevsky S. M., Kalmykov A.V. On condition monitoring and tuning of brush-contact devices of turbogenerators. Electronic publication on the website "Electric networks": https://leg.co.ua/arhiv/generaciya/o-kontrole-sostoyaniya-inastroyke-schetochno-kontaktnyh-apparatovturbogeneratorov.html. (in Russian).

[9]. Theory of systems with variable structure // Emelyanov S. V., Utkin V. I., Taran V. A., et al. Ed. Emelyanova S. V. - M.: Nauka. 1970. 592 p. (in Russian).

[10]. Haken G. Synergetrics. M.: World. 1980. 400 p. (in Russian).

[11]. Haken G. Synergetrics Hierarchy of instabilities in self-regulating systems. M.: World. 1985. 419 p. (in Russian).

[12]. Fuller B.R. Sinergetics. N.Y.: MacMillan. 1982. 350 p. 